\title{
Dipeptidyl peptidase-4 inhibitors for treatment of type 2 diabetes mellitus in the clinical setting: systematic review and meta-analysis
}

There is an error in this Research paper by Karagiannis and colleagues (BMJ 2012;344:e1369, doi:10.1136/bmj.e1369) and in our previously published correction (BMJ 2012;345:e4959). In the final paragraph of the section "Glycaemic efficacy," the risk ratio in favour of GLP-1 agonists should have been 1.82, $95 \%$ confidence interval 1.50 to $2.21 ; \mathrm{I}^{2}=0 \%$ [not " $1.33,1.09$ to $1.63 ; \mathrm{I}^{2}=26 \%$ " as published in the original paper, or " 1.82 , $95 \%$ confidence interval 1.50 to $2.21 ; \mathrm{I}^{2}=26 \%$ " as published in the previous correction].

Cite this as: BMJ 2012;345:e5129

๑ BMJ Publishing Group Ltd 2012 